\title{
Pattern of Dental Clinic Attendance of Registered Diabetic Patients in Ibadan
}

\author{
Juliana O. Taiwoa, Moronke Noah ${ }^{a}$
}

\begin{abstract}
A study on a stratified sample of 120 adult registered diabetic patients from the only two diabetes clinics in Ibadan, University College Hospital (UCH) and Ring Road Government Hospital and fifty (50) healthy adult nondiabetic volunteers as control, shows that 51.48\% of the interviewees have never visited the dental clinic in their lifetime. Also $43.3 \%$ of both diabetes and healthy control groups have not visited the dental clinic for more than one year. The mean duration since their last visit was 3.47 yrs (SD $\pm 2.48 y r s)$. Interviewees with higher educational status; post-Secondary School Higher Education, had statistically significant lower percentage frequency of nonattendance $15.79 \%(P<0.0053)$. The percentage frequency of regular attendance among women was significantly higher than among men, 9.1\% and 5.0\% ( $<<0.0005)$ respectively. Dental clinic attendance in the healthy control is comparable to the attendance of the study group. Although more diabetic patients than the healthy control group attended the dental clinic occasionally due to one problem or another, this was not statistically significant. (chi sq=0.68 $\mathrm{P} \leq 0.44$ ). Toothache was the greatest facilitator of dental clinic attendance. The greatest barrier to the dental clinic attendance of diabetic patients as well as the healthy control group was lack of perceived need for dental care.
\end{abstract}

\section{INTRODUCTION}

"The overriding concern of all health professionals, however, is that, effective treatment of physical and oral conditions always depend upon the patients initiative in seeking diagnosis and treatment ${ }^{1}$."

Dental clinic attendance, teeth cleaning frequencies and conscious reduction of sugary food consumption are indicators of dental health behaviour ${ }^{2}$. As early as 1849 George Quick Shank made reference to the six monthly dental clinic visits ${ }^{3}$. However Sheiham is opposed to the six monthly dental clinic visits Reasons being that it is not based on the life history of the major dental diseases,

KEY WORDS: Dental Clinic attendance, diabetes mellitus, facilitators, Dental infections

aDepartment of Preventive Dentistry, College of Medicine, P.M.B 5116, Ibadan, Nigeria.

(0 CMS UNIBEN JMBR 2006; 5(1):36-43 it encourages unnecessary intervention because there are more false positive decisions the more frequently people are examined, it creates dependency on dentists and it is unnecessary waste of resources ${ }^{4}$. With the emergence of the current concepts of remineralization and demineralisation and its implication in the prevention of caries, the relevance of the six monthly dental clinic visits has been potentiated ${ }^{5}$. Much information accrued on dental clinic attendance are from studies in the developed countries ${ }^{6}$. Whilst very few studies have been conducted in Africa, virtually no information exists on the dental clinic attendance pattern of Nigerians. Acute metabolic complications and infections, being the most important causes of death in diabetic patients, well-informed diabetics would take precautions against any form of infections including infections of the oral cavity. This would be the expectation of 
all health professionals comitted to the care of such patients. It is the objective of this study to elucidate the dental clinic attendance pattern of registered diabetic patients in lbadan.

\section{MATERIALS AND METHODS}

The study was conducted on a stratified sample of 120 adult, registered, diabetic patients. attending University College Hospital (U.C.H.) and Ring Road Government Hospital. the only two government diabetes clinics in lbadan. The above sample included seventy five (75) patients from U.C.H. and forty-five(45) patients from Ring Road Government Hospital. The control group included 50 healthy adult non-diabetic volunteers, within the same age range as the diabetic patients (22 yrs - 83yrs), attending a private hospital, Mobolaji Hospital, Ibadan. Assessment of metabolic control of diabetic patients was from fasting blood glucose tests (F.B.G. ) . For diabetic patients from U.C.H. the F.B.G. results of the month they were interviewed was recorded from their hospital records. Many diabetic patients from Ring Road Hospital could not afford the blood test and depended on the urine test. Consequently, their blood samples were taken and the FBG test was conducted for them at U.C.H. Fasting glucose test was conducted for the volunteers to confirm that they were not diabetic.

The subjects were grouped into uncontrolled N.I.D.D.M, (Non-Insulin Dependent Diabetes Mellitus), uncontrolled I.D.D.M., (Insulin Dependent Diabetes Mellitus) controlled N.I.D.D.M.I, uncontrolled I.D.D.M. and healthy control, depending on the method of diabetes control and their fasting blood glucase result. F.B.G. results equal to or below $6.3 \mathrm{mmol} / 1$. was regarded as controlled and values more than the above value as uncontrolleơ

The interviewers explained the nature of the study to the subjects, interviewed and filled the questionnaires for them. Interviewers interviewed diabetic patients from both hospitals on diabetes clinic days, consecutively, until the required number for each hospital was met. Participating volunteers were given appointment to come to the private hospital for the interview and fasting blood glucose test.

The questionnaires consisted of coded questions enquiring into the oral health complaints of subjects, their dental clinic attendance pattern, reasons for nonattendance and attendance, educational status, occupation, social habits (such as. smoking or chewing kola nuts) dental health knowledge, behaviour and attitude, as well as their intention to visit the dental clinic again. For diabetic patients it included questions on the method of diabetes control used and duration of diabetes.

From the information obtained participants were grouped into nonattenders, regular attenders and in trouble attenders depending on the following variables:
(a) Time interval since last visit
(b) Purpose of visit, whether it was solely for maintenance of dental health or cure of symptoms
(c) Intention to visit the dental clinic again.

An attender whose last visit was within the last 1 year, whose purpose of visit was solely to maintain dental health and intends to visit the dental clinic again was accepted as a regular attender. Visits made for the purpose of check ups, fluoride application against caries and professional cleaning (scaling and polishing), were regarded as health maintenance purposes.

An attender whose last visit was more than a year was regarded as an in trouble attender. 'An attender even though the last visit was within I yr, was regarded as an in trouble attender if the purpose of his visit was for cure of symptoms and has no intention of visiting the dental clinic again. Attenders who have never visited the dental clinic before were classified as nonattenders. 
The data was analysed using the SPSS Computer Software as well as manually. The frequency distribution and the percentage frequency of the variables were determined. Chi square test was used to determine association between variables and the $\mathrm{P}$ value was used to determine the significance of the association.

\section{RESULTS}

Nine U.C.H. diabetic patients whose hospital records were not accessible and 10 Ring Road diabetic patients, who had eaten before the test, were excluded from the study. Of the 50 healthy control subjects, 14 were excluded when they refused to have blood samples taken from them for the F.B.G. test. The remaining 36 healthy control subjects, included 10 males and 26 females with a mean age of 44 years (SD \pm 17 years) and mean FBG of $3.2, \mathrm{SD} \pm 1.16 \mathrm{mmol} / 1)$. Fifty- one females and 50 males constituted the 101 diabetics in the study group. Twenty-two (21 .78\%) suffered from I.D.D.M. whilst 79 of them (78.22\%) from N.I.D.D.M. The 6 controlled I.D.D.M patients consisted of 3 males and 3 females with a mean age of 40 years (SD \pm $17.3 \mathrm{yrs}$ ) and mean duration of diabetes of 18 years. Sixteen males and 17 females constituted the 33 controlled NIDDM patients, with a mean age of 59.5 years (SD \pm 11.18 years) and a mean duration of diabetes of 7 years. The 46 uncontrolled NIDDM patients included 24 males and 22 females with a mean age of 57.44 years (SD \pm 11.23 years) and a mean duration of diabetes of 10 years. Seven (7) males and 9 females constituted the 16 uncontrolled IDDM patients with a mean age of 43.61 years (SD \pm 18.75 years) and a mean duration of diabetes of 10 years. The mean FBG of the interviewees is depicted in Table 1.

Table 1: Mean FBG Values of Subjects in the Study

\begin{tabular}{|l|l|l|l|l|l|}
\hline & $\begin{array}{l}\text { HEALTHY } \\
\text { control } \\
\mathrm{n}=36\end{array}$ & $\begin{array}{c}\text { NIDDM } \\
\text { controlled } \\
\mathrm{n}=33\end{array}$ & $\begin{array}{c}\text { IDDM } \\
\text { controlled } \\
\mathrm{n}=6\end{array}$ & $\begin{array}{c}\text { NIDDM } \\
\text { uncontrolled } \\
\mathrm{n}=46\end{array}$ & $\begin{array}{c}\text { IDDM } \\
\text { uncontrolled } \\
\mathrm{n}=16\end{array}$ \\
\hline $\begin{array}{l}\text { Mean FBG } \\
\text { value mmol/1 }\end{array}$ & $3.2(\mathrm{SD} \pm 1.16)$ & $4.5(\mathrm{SD} \pm 1.17)$ & $4.38(\mathrm{SD} \pm 1.77)$ & $11.14(\mathrm{SD} \pm 3.59)$ & $12.1(\mathrm{SD} \pm 5.38)$ \\
\hline
\end{tabular}

Table 2: Attendance Pattern of Diabetic Patients and Healthy Control Interviewees

\begin{tabular}{|c|c|c|c|}
\hline BDIABETES STATUS & $\begin{array}{l}\text { NON } \\
\text { ATTENDERS }\end{array}$ & $\begin{array}{l}\text { IN } \\
\text { TROUBLE } \\
\text { ATTENDERS }\end{array}$ & $\begin{array}{l}\text { REGULAR } \\
\text { ATTENDERS }\end{array}$ \\
\hline CONTROLLED IDDM & $(\mathrm{N}=6) 4(66.7 \%)$ & $2(33.3 \%)$ & $0(0 \%)$ \\
\hline CONTROLLED NIDDM & $(\mathrm{N}=33) 17 \quad(51.5 \%)$ & $15(45.45 \%)$ & $1(3.9 \%)$ \\
\hline UNCONTROLLED NIDDM & $(\mathrm{N}=46) 21 \quad(45.6 \%)$ & $22(47.8 \%)$ & $3(6.5 \%)$ \\
\hline UNCONTROLLED IDDM & $(\mathrm{N}=16) 10 \quad(62.5 \%)$ & $4(25 \%)$ & $2(12.5 \%)$ \\
\hline & TOTAL 52 (51.5\%) & $43(42.6 \%)$ & $6(5.9 \%)$ \\
\hline HEALTHY CONTROL & $20(55.6 \%)$ & $12(33.3 \%)$ & $4(11.10 \%)$ \\
\hline
\end{tabular}

Chi sq. test Yates corrected $=0.68 P \leq 0.44$

Response rate 100\%

(0 CMS UNIBEN JMBR 2006; 5 (1):36-43 
Table 2 delineates attendance pattern of diabetic patients and the healthy control. Table 2 expresses the large percentage of nonattendance in diabetes and healthy control groups. A high percentage of both diabetics (51.5\%) and healthy control (55.6\%) groups have not visited the dental clinic for more than one year. 'The mean duration since their last visit was 3.47 years (SD \pm 2.48 yrs). More diabetic patients than the healthy control group attended the dental clinic occasionally because of one problem or another but this was not statistically significant. (Chi sqaure test Yates corrected $0.68 \mathrm{P}=0.44$ )

Table 3 illustrates the pattern of dental clinic attendance in relation to their educational status. The percentage frequency of illiterates in the study group was higher that literates. Higher educational status, post secondary school higher education (polytechnic and university graduates) had lower percentage frequency $15.79 \%$ of nonattendance and a relatively high percentage frequency of regular attendance (chi sq Yates corrected $31.12 \mathrm{P} \leq 0.005)$.

Figure 1 depicts reasons given for nonattendance. The most frequent reason being "I have no problem." Figure 3 features reasons given for dental clinic attendance. The least motivational factor was check up whilst, toothache was the most frequent facilitator of in trouble attendance. Also 7 (9.1\%) of the women as compared to 3 (5.0\%) of the men in the study group attended the clinic regularly. (chi sq Yates corrected $=12.82 \mathrm{P}$ value $0.0005)$. Whilst 29 (37.7\%) of women and 26 (43.3\%) of men attended the clinic only when they had problems. In addition 41 (53.2\%) of women and 31 (51.7\%) of men have never been to the dental clinic.

\section{DISCUSSION}

Dental clinic attendance, teeth cleaning frequencies and conscious reduction of sugary food consumption are indicators of dental health behaviour. ${ }^{2}$

Despite the great improvement brought about by antibiotics, insulin and improved methods of glyceamic control, infection still accounts for much morbidity and mortality in diabetics, more so in developing countries ${ }^{9}$. The frequent association of periodontal disease and diabetes especially uncontrolled diabetes makes dental health a very important subject in the life of diabetics. Various studies have demonstrated the extent of periodontal disease and various pathologies encouraging its progress in diabetics. Microangiopathy, altered leucocyte chemotaxis, increased dental plaque and calculus formation and abnormal collagen metabolism all contribute to the vulnerability of diabetics to dental infections. ${ }^{10},{ }^{11}$. Factors such as oral hygiene, duration of diabetes, age and degree of metabolic control influence the severity of periodontal disease in diabetics ${ }^{12}$.

Table 3: Attendance Pattern According To Educational Status

\begin{tabular}{|l|l|l|l|r|}
\hline Educational Status & $\begin{array}{l}\text { Regular } \\
\text { Attenders }\end{array}$ & $\begin{array}{l}\text { In Trouble } \\
\text { Attenders }\end{array}$ & $\begin{array}{l}\text { Non } \\
\text { Attenders }\end{array}$ & Total \\
\hline Illiterate & $1(1.64 \%)$ & $23(37.70 \%)$ & $37(60.66 \%)$ & 61 \\
\hline Primary School & $5(19.23 \%)$ & $7(26.92 \%)$ & $14(53.85 \%)$ & 26 \\
\hline Secondary School & $1(5.26 \%)$ & $5(26.32 \%)$ & $13(68.42 \%)$ & 19 \\
\hline Post Secondary School Skill Training & 0 & $3(42.86 \%)$ & $4(57.14 \%)$ & 7 \\
\hline Post Seconday School Higher Education & $3(15.79 \%)$ & $13(68.42 \%)$ & $3(15.79 \%)$ & 19 \\
\hline Others (Arabic Studies) & 0 & $4(80 \%)$ & $1(20 \%)$ & 5 \\
\hline Total & 10 & 55 & 72 & 137 \\
\hline
\end{tabular}

(Chi-square Yates corrected $=31.12$ PS0.005) 


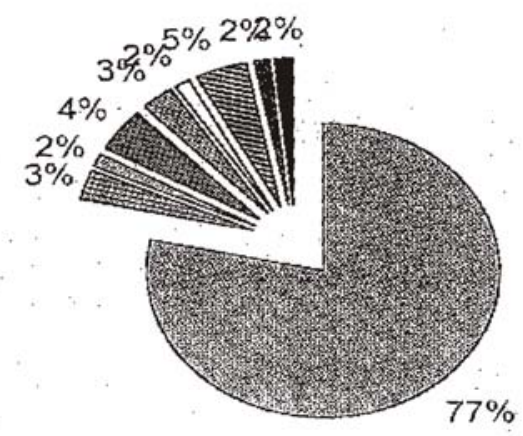

\begin{tabular}{|c|c|c|}
\hline Toothache & 圈 Checkup & Accidents \\
\hline caling and Polishing & Mobile teeth & $\square$ Gum problem \\
\hline Extraction & Dentures & Referred \\
\hline
\end{tabular}

\section{Fig 3: Facilitators of Dental Clinic Attendance of Interviewees}

Research on dental clinic attendance has witnessed over reporting of regular attendance ${ }^{13}$. The method of analysis used to determine attendance in this study aims at reducing errors due to over reporting of regular attendance. From observation, a participant's definition and understanding of regular attendance was more tied to his perception of dental health. Thus, participants with lay concepts or low perception of dental health are more likely to view dental attendance with long regular intervals, (more than a year), as a regular visit. This prompted the need to differentiate the true regulars as perceived by the dentist from the false regulars as perceived by the patient. It was observed that some in trouble dental clinic attenders last visit happen to fall within the one year interval.

The definition of regular attendance in dentistry is more associated with the number of times the individual has attended the dental clinic in a year. In the authors opinion, the definition should go further to include the purpose for which the visits were made. The purpose for which the visits were made indirectly informs us of the intention for which they were made. If consideration is to be given to the definition of health behaviour more emphasis should be attached to the intention for which the visits were made. Hence the development of this methodology . Thus, a regular attender as classified by the above methodology will attend the dental clinic regularly within the limit of one year, regardless of the state of his dental health.

More than $50 \%$ of diabetics in lbadan have not attended the dental clinic in their lifetime. This observation should not be misconstrued as an indication of good oral health. Observations from a previous study in the same study group have indicated high-perceived oral health needs in this group ${ }^{14}$. Dental clinic attendance in the healthy control is comparable to the attendance of the study group. The pattem of dental clinic attendance of diabetics in lbadan may therefore be a reflection of the pattern of dental clinic attendance of the community at large. The results confirm other studies in which women exhibited a more regular attendance pattern than the men ${ }^{15}$. The difference between diabetics and healthy control who attended the dental clinic occasionally because of one dental problem or another was statistically significant . This should not be interpreted as an indication of better dental health behaviour of diabetics

(. CMS UNIBEN JMBR 2006; $5(1)$ : 36-43 
over the healthy control. In fact it should be regarded that diabetics had more oral health problems and were compelled to visit the dental clinic. This observation was confirmed by percentage of regular attendance, which was higher in the control than the study group. NIDDM groups as compared to the IDDM groups had a higher percentage of in trouble attendance. This most probably may be due to the higher mean age in this group. The influence of age on the severity of periodontal disease in diabetics has already been discussed in a previous chapter. educational status had a significant influence on regular dental clinic attendance confirming findings from previous studies ${ }^{15}$. In this environment, educational status has a great influence on the social class of individuals. Considering that very little effort is made to keep the public informed about their dental health, the educated person has more access to information through reading. Locker ${ }^{16}$ reviewing published articles on the relationship between socioeconomic status and dental disease, observed that, adults on low incomes or with lowest levels of education, have the worst oral health experience.

In Nigeria, there is limited information on the socioeconomic aspect of dental care in adults. Studies carried out in children, have revealed a great disparity between the oral hygiene status, as well as the gingival health of children from the lower socioeconomic class and children from the higher socioeconomic class ${ }^{17,18}$. Globally the people from the lower socioeconomic group have poorer oral hygiene and gingival health status ${ }^{16}$. Whilst, the prevalence of caries is higher in the lower socioeconomic class in the industrialized countries ${ }^{19}$, the caries experience of Nigerians exhibits a reverse pattern ${ }^{20}$.

Regular dental clinic attendance is one of the four preventive oral health behaviours recommended and promoted by the health Educationist ${ }^{2}$. Health behaviour is the action taken by an individual who considers himself healthy, for the purpose of preventing disease or detecting it at an early stage ${ }^{21}$. Regular dental clinic attendance has been referred to as secondary prevention ${ }^{22}$. The sole purpose for a regular dental visit is to prevent a disease or detect it at an asymptomatic stage. This means that, an individual who goes to the dental clinic for a check-up, considers himself healthy and is only taking precautions to maintain his state of health. The dentist may or may not find any disease manifestation in such a patient. Reference to regular dental clinic attendance as secondary prevention, assumes that dental disease is inevitable in every patient who comes for a check up. This will encourage over treatment especially in privately and publicly financed organisational structures of health such as capitation. Dental clinic attendance as illustrated by in trouble attendance could be an interpretation of illness behaviour and could therefore be referred to, as secondary prevention.

Illness is the subjective interpretation of problems which are perceived to be health related ${ }^{23}$. It is more the experience of symptoms and their consequences ${ }^{23}$. Illness expressions are socially learnt ${ }^{23}$. Lay health concepts and illness interpretation are influenced by a variety of factors such as social class, culture, knowledge, values and believes of the community ${ }^{19}$. Lay concepts of health associates health with robustness, the ability to carry out physical activities and expressing emotions such as happiness ${ }^{24}$. With the above lay concepts of health, lay people will not consider dental problems illness unless it interferes with their daily activities. This explains why, toothache is the greatest facilitator of dental clinic attendance. Also this obviously may be contributory to the low percentage frequency of regular dental clinic attendance in this study.

A study conducted on the dental health beliefs of Yoruba indigenous commu-nities revealed that, the individual is responsible for afflicted choices, resulting in illness, either directly or through the supernatural ${ }^{25}$. This was attributed to failure to perform stipulated

( CMS UNIBEN JMBR 2006; 5 (1) : 36-43 
rituals, protective routines or remedies, such as herbal prepara-tions, tonics taken routinely by mothers, or child to ensure general well being and protection from potential and existing enemies ${ }^{25}$. Herbs may be taken alone or may be accompanied by prayers, incantations and invocations ${ }^{25}$. The majority of the inhabitants in Ibadan are Yoruba. From the above information, it is obvious that the concepts of prevention has always been part of the Yoruba culture, except that efforts towards prevention has been misdirected and based on erroneous believes. The above health belief may lead to the development of complacency towards dental health, create a false sense of security and will not likely encourage regular dental clinic attendance.

\section{CONCLUSION}

Whilst lack of regular dental clinic attendance in non-diabetics, may create concern among dentists, in diabetics it is not desirable and regular dental clinic attendance is imperative in this high-risk group.

Success in diabetes care could be achieved when the need for dental care is allied with other health needs, such as the need to control infection and therefore diabetic complications. The pattern of dental clinic attendance in diabetics was quiet similar to the pattern of dental clinic attendance of the control. More diabetics had a higher percentage of in trouble attendance than the control group. Participants with higher educational status had a higher percentage of regular attendance.

\section{RECOMMENDATIONS}

Periodontal diseases as well as dental infections should be given equal attention as other infections such as ear infections, lung infections, foot ulcers which are partisan to complications in diabetics.

The oral health of these patients is therefore of outmost importance, not only to the dentist, but also to diabetes health workers

(ㄷ CMS UNIBEN JMBR 2006; 5 (1) : 36-43 and regular dental clinic attendance should be an essential aspect of prevention of complications in these patients.

The socioeconomic aspect of dental care is an area that offers much opportunity for research in Nigeria. Findings from such research will contribute greatly to the improvement of oral health care in Nigeria.

\section{ACKNOWLEDGEMENT}

The authors would like to acknowledge the valuable contributions of the Director and Staff of Mbbolaji Hospital, Residents and staff of the diabetic unit of University College Hospital and Doctors and Staff of the diabetic unit of Ring Road Government Hospital. Also the authors would like to thank all diabetics and volunteers who participated in the programme.

\section{References}

1. Locker D. Illness behaviour, need and demand for dental care. An introduction to behavioural Science and dentistry 1989; 102 $-103$.

2. Health education authority. The Scientific basis of dental health education, a policy document $3 r d$ edition London. Health Education Authority 198913 - 14 .

3. Sheiham A. The limitations of Dentistry. Community dental health, Monograph Series. 1986; 12.

4. Sheiham A. Is there a scientific basis for the six monthly dental examination? The Lancet 1977; 11:442 - 444.

5. Elderton R.J. Six monthly examinations for dental caries. Bri dent J. 1985; 158:370 - 374.

6. Sheiham A., Maizel J. Cushing A. and Holmes J. Dental attendance and dental status. Community dent oral epidemiol 1985; 13:304 - 309.

7. Tweneboa NA. Diabetes M. An educational booklet. Practical diabetes Digest, 1991; 283 -284 .

8. Ohwovoriole A. E. . Fasanmade O.A., Johnson T.O. Assessment of diabetic control. An 
African perspective. Diabetes International Digest. $1994 ;$ 5:2-47.

9. Rifat Naghmi, Skin disorders in diabetes mellitus. International Diabetes Digest. 1993; 4:3-5

10. Sandholm L. Swanlgung O., Rytomaa 1, Kaprio E.A., Meanpaa J. Morphotypes of subgingival microflora in diabetic adolescents in Finland. J. Periodontol. 1989; 95: $26-29$

11. Wilson T.G. Periodontal disease and diabetes. Diabetes Education. 1989 ; 15: 342-345

12. Katz P.P. Wirthlin M. R. Jr. Szpunar S.M., Selby J.V., Sepe S.J., Showstack J.A. Epidemiology and prevention of periodontal disease in individuals with diabetes. Diabetes Care. 1991; 14; 5: 375-378

13. Grant D.A. Stern 1. B., Listgarten M. A. Epidemiology, etiology and public health aspects of periodontal disease. Periodontics in the tradition of Gottlieb and Orban C.V. Mosby company Washington D.C. 1988: 231.

14. Taiwo, J. 0. Oral health needs and barriers to oral health care of patients with diabetes in Ibadan. Afri J Med Practice .1997; Vol. $42: 51-63$.

15. Manga P.. Charette A. The patterns and determinants of the utilization of dental care services in Canada. Canad J of Public Health .1986; 77; Supplement 1:119-123.

16. Locker D. Inequalities in health and dental health. An introduction to behavioural science and dentistry. Routledge. 1989:39 - 58.
17. Taiwo, J. O. Social class distribution of Necrotising ulcerative gingivitis. Afri J of Med, med sci. 1996; 25: 357-360.

18. Enwonwu. C.0. Review of oral diseases in Africa and influence of socioeconomic factors. Int. Dent. J. 1981: 29 - 38.

19. Carmichael. C. , Rugg-Gunn A., French A and Cranage $J$. The effect of fluoridation upon the relationship between caries experience and social class in 5 year old children in New Castle and Northumberland, Bri. Dent. J .1980; 149: 163 - 167.

20. Noah, R. Caries experience and oral cleanliness in deciduous dentition of lbadan children from different social groups. J. Int. Assoc. Dent. Child .1984; 143: 143-149.

21. Kasl S. and Cobb S. Health behaviour, illness behaviour and sick role behaviour Archives of Environmental health $.1966 ; 12: 246-266$

22. Maizel I. Maizel A. . Sheiham A. Dental disease and health behaviour, the development of an interactional model, Community Dent health .1991; 8: 311 - 321.

23. Freidson E. Profession of Medicine. New York. Dodd Mead \& Co. 1970.

24. Hunt S.M. Macleod M. Health and behaviourial change, some lay perspective. Community medicine .1987; 9: (1) : 68-76.

25. Adewakun A. Oral health perceptions and practices in two Nigerian communities University of London (dissertation). 1989:70-80. 